Research Journal of Medical Sciences 4 (3): 111-115, 2010

ISSN: $1815-9346$

(C) Medwell Journals, 2010

\title{
Fermentation of Aflatoxin Contaminated White Dent Maize (Zea mays)
}

\author{
${ }^{1}$ A.S. Adegoke, ${ }^{2}$ J.A. Akinyanju and ${ }^{3}$ J.E. Olajide \\ ${ }^{1}$ Department of Microbiology, Kogi State University, Anyigba, Nigeria \\ ${ }^{2}$ Department of Biological Sciences, University of Ilorin, Ilorin, Nigeria \\ ${ }^{3}$ Department of Biochemistry, Kogi State University, Anyigba, Nigeria
}

\begin{abstract}
White dent maize was sorted manually into apparently clean and visibly spoilt maize samples. The maize samples were pulverized and fermented for Ogi production. The clean and spoilt maize samples had 11.8 and $18.6 \%$ moisture content, respectively. During fermentation, the concentration of aflatoxin B present in the apparently clean white dent maize slurry rose from $0.98 \mu \mathrm{g} \mathrm{mL}^{-1}$ at day $0-1.05 \mu \mathrm{g} \mathrm{mL}^{-1}$ at day 1 while for visibly spoilt white dent maize slurry the concentration rose from $2.20 \mu \mathrm{g} \mathrm{mL}^{-1}$ at day $0-2.55 \mu \mathrm{g} \mathrm{mL}^{-1}$ at day 1 . The study also shows the persistence of aflatoxin B throughout the fermentation period with concentrations remaining at 1.05 and $2.55 \mu \mathrm{g} \mathrm{mL}{ }^{-1}$, respectively for both samples. Fermentation was accompanied with decrease in $\mathrm{pH}$ of the slurry from 6.0 at day $0-4.0$ at day 3 for apparently clean white dent maize slurry and 5.8 at day $0-4.0$ at day 3 for visibly spoilt white dent maize slurry. There was a corresponding increase in the titratable acidity from 0.2 at day $0-1.1$ at day 3 and 0.4 at day $0-2.3$ at day 3 , respectively. This study shows a deleterious health hazard in the continuous use of aflatoxin $\mathrm{B}$ contaminated maize in Ogi production.
\end{abstract}

Key words: Aflatoxin, aflatoxigenic, persistence, fermentation, maize, production

\section{INTRODUCTION}

Fermentation is one of the oldest and most economical methods of processing and preserving foods (Chauvan and Kadan, 1989). A fermented food is one with one or more of its constituents acted upon by microorganisms to produce a considerably altered final product acceptable to human use (Van Veen and Steinkraus, 1970).

Fermented foods provide varieties in the diet (Kordylas, 1990), increase water-soluble vitamins (Van Veen and Steinkraus, 1970) and improve organoleptic properties and digestibility (Chauvan and Kadan, 1989).

In developing countries like Nigeria, fermentation techniques are passed on as trade secrets in the families of certain communities, a practice protected by tradition. Moreover, fermented foods constitute a significant component of the diets mostly in the rural areas. The traditional food processing system which involves use of maize is diversified and a large variety of foods are produced and sold by food processing micro enterprises. The high temperature and high humidity coupled with unsanitary conditions in tropical countries favored food spoilage and pathogenic microorganisms (Nout and Rombouts, 1992).

Aflatoxins are one of the most potent toxic substances that occur naturally. They are produced by Aspergillus flavus and A, parasiticus (Polster et al., 1990).
They are classified as a group one carcinogen and have been confirmed as a potential carcinogen in agricultural product (IARC, 1993). Metabolism plays a major role in deciding the degree of toxicity (Eaton and Gallagher, 1994).

Aflatoxin 8, 9 epoxide, one of the metabolites of aflatoxin metabolism can induce mutation by intercalating into DNA by forming adduct with guanine moiety in the DNA (Smela and Sophie, 2001). Moreover, species susceptibility to aflatoxin is mainly dependent on its liver detoxification system, genetic make-up, age, environmental factor, exposure level and nutritional status of diet (Howard and David, 1990).

Various studies have shown statistical relationship between hepatoma and consumption of aflatoxin (Neto, 1981) as found in Swaziland (Keen and Martin, 1971), Uganda (Alpert et al., 1971), Kenya (Peers and Linsell, 1973); Mozambique (Van Ransburg et al., 1975), Nigeria (Bababunmi et al., 1977) and exposure and incidence of liver cancer (Groopman and Wild, 2001). Aflatoxin is relatively stable to heat (Rehana and Bassapa, 1990). Ugali and bread prepared from contaminated maize and wheat retained 85.5 and $82.4 \%$ aflatoxin $B$ and $G$, respectively in Ugali while the bread retained 83.8 and $67.8 \%$ aflatoxin B and G, respectively (Seenappa and Nyagahungu, 1983). Undoubtedly, there is a pertinent need to prevent aflatoxin production. However, maize grains cannot be free of fungal propagules, hence any attempt to control

Corresponding Author: A.S. Adegoke, Department of Microbiology, Kogi State University, Anyigba, Nigeria 
the occurrence of mycotoxins requires the development of efficient analytical procedure so that the levels of consumption in foods may be accurately monitored. This study tends to establish the food safety and possible health hazard as it relates to the possibility of the presence of aflatoxin in fermenting maize.

\section{MATERIALS AND METHODS}

Source of maize: Maize samples used in this study were commercial low moisture white dent bought from Emir's market in Ilorin, Kwara State, Nigeria.

Sorting of maize: Maize grains were manually separated in to clean and visibly spoilt maize manually based on visual examination. Physical damage, decay, insect injury, discoloration, moldy appearance, chipped and broken defined visibly spoilt maize.

Moisture level determination: About $80 \mathrm{~g}$ of each samples of the sorted maize grains were weighed in to aluminum dish and heated in a Gallenkamp oven Bs model ov-330 at $105^{\circ} \mathrm{C}$ and weighed periodically until constant weight was obtained (AOAC, 1984). The percentage moisture present was calculated with the formula:

$$
\text { Moisture }(\%)=\frac{\text { Weight of water loss }}{\text { Weight of maize before drying }} \times 100
$$

Typing for aflatoxin presence in maize samples: About $50 \mathrm{~g}$ of each maize sample were weighed in to sterile $500 \mathrm{~mL}$ conical flask. About $100 \mathrm{~mL}$ of chloroform was added to each conical flask and shaken vigorously on orbital shaker at $120 \mathrm{rpm}$ for $20 \mathrm{~min}$. The chloroform extract was filtered through dried No. 1 Whatman filter paper.

Clean up of extract: Basic green cupric carbonate powder was added to the crude chloroform extract at the rate of

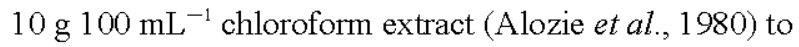
remove yellow pigment. Excess cupric carbonate and cupric carbonate bound yellow pigment were separated by filtration using dried No. 1 Whatman filter paper.

\section{Analysis of aflatoxin}

Qualitative analysis: The clear chloroform extract of each maize sample was evaporated to dryness in a rotary flask evaporator. The residue of each maize sample extract was redissolved in $2 \mathrm{~mL}$ of reagent grade chloroform. Aliquot of each maize sample extract was subjected to thin layer chromatography on silica gel plates by spotting the aliquot approximately $4 \mathrm{~cm}$ from the bottom of the $20 \times 20 \times 0.3 \mathrm{~cm}$ chromatographic plate (Anon, 1975). The spots were placed $2 \mathrm{~cm}$ apart and the plate was developed to a distance of $15 \mathrm{~cm}$ in an unlined developing tank containing chloroform: acetone (9:1) solvent system. The plate was dried at room temperature and later observed under ultraviolet light using the chromato-vue cabinet at $365 \mathrm{~nm}$. The patterns of fluorescent spots were observed and the colour noted with the $\mathrm{R}_{\mathrm{f}}$.

Quantitative: This was done by the spectrophotometric method of Roderick and Stoloff (1970). The concentration of the two aflatoxin extracts prepared by redisolving the aflatoxin spot from the silica gel in chloroform was determined by measuring the absorbance (A) with a spectrophotometer (SP8-150 uv/vis PYE UNICAM) at $365 \mathrm{~nm}$ against chloroform as the blank. The concentration of each type of aflatoxin was calculated with the formula:

$$
\text { Conc. of aflatoxin } \mu \mathrm{g} \mathrm{mL}^{-1}=\frac{\mathrm{A} \times \mathrm{MW} \times 100 \times \mathrm{CF}}{\mathrm{E}}
$$

Where:

A $\quad$ Optical density

$\mathrm{MW}=$ Molecular weight

$\mathrm{E}=$ Molar absorptivity

$\mathrm{CF}=$ Correlation factor (obtained from calibration of instrument)

The molecular and molar absorptivity were taken from the table provided by Roderick and Stoloff (1970).

Confirmation of aflatoxin: The characteristic fluorescence properties and $R_{f}$ value provided confirmation of the presence of the presumptive aflatoxin as observed under ultraviolet light at $365 \mathrm{~nm}$. The chromatographic plate was also sprayed with $10 \% \mathrm{H}_{2} \mathrm{SO}_{4}$ in methanol. A bright yellow spot also confirmed aflatoxin (Romer, 1975). Finally, the chloroform extract was derivatized withTrifluoroacetic Acid (TFA) to convert the naturally occurring aflatoxin to more intensely fluorescent hemiacetals (AOAC, 1984). These features were compared with a know aflatoxin standard.

Fermentation of maize samples: About $200 \mathrm{~g}$ of pulverized samples of the apparently clean maize and visibly spoilt maize were introduced in to separate clean sterile $1000 \mathrm{~mL}$ conical flask. About $400 \mathrm{~mL}$ of sterile tap water was added into each conical flask. The two flasks were stoppered with cotton wool and incubated at room temperature $27 \pm 2^{\circ} \mathrm{C}$ for 3 days for the maize to ferment.

Determination of $\mathbf{p H}$ and titratable acidity: The $\mathrm{pH}$ of the maize slurry was measured with a PYE unicam $\mathrm{pH}$ meter (292 MK 2) at interval of $24 \mathrm{~h}$ until the end of the fermentation process. The method of Kirk and Sawyer (1991) was used to determine titratable acidity. 
Aflatoxin behavior during fermentation: About $40 \mathrm{~mL}$ of water and $0.6 \mathrm{~g} \mathrm{NaCl}$ was added to $30 \mathrm{~mL}$ of each slurry sample in a $500 \mathrm{~mL}$ conical flask. The flask was shaken vigorously in an orbital shaker at $120 \mathrm{rpm}$ for $10 \mathrm{~min}$. About $40 \mathrm{~mL}$ of the flask content was added to $7 \mathrm{~mL}$ ethanol and $20 \mathrm{~mL}$ hexane in a $500 \mathrm{~mL}$ conical flask. The content was again shaken in an orbital shaker for $4 \mathrm{~h}$ at $120 \mathrm{rpm}$. Centrifuging at $2000 \mathrm{rpm}$ for $5 \mathrm{~min}$ separated the methanol water extract. Adding $25 \mathrm{~mL}$ of $17 \% \mathrm{NaCl}$ solution to $50 \mathrm{~mL}$ methanol extract diluted the methanol extract. About $75 \mathrm{~mL}$ of the resultant solution was washed with $50 \mathrm{~mL}$ chloroform in a separating funnel and subjected to analyses for aflatoxin.

\section{RESULTS AND DISCUSSION}

Moisture level determination: The average moisture level of the apparently clean white dent maize was found to be $11.8 \%$ while that of the visibly spoilt white dent maize was found to be $18.6 \%$.

Determination of $\mathbf{p H}$ : The $\mathrm{pH}$ changes that occurred during the fermentation of white dent maize sample slurries are shown in Fig. 1a. There was a decrease in the $\mathrm{pH}$ from day $0-3$ in both maize sample slurries. For apparently clean white dent maize slurry it decreased from 6.0 at day $0-4.0$ at day 3 while for visibly spoilt white dent maize slurry it decreased from 5.8 at day $0-4.0$ at day 3 (Fig. 1a).

Determination of titratable acidity: The result of titratable acidity carried out during fermentation of white dent maize slurries are shown in Fig. 1b. There was an increase in the titratable acidity from day 0-3 day for both maize samples. For apparently clean white dent maize slurry it increased from 0.2 at day $0-1.1$ at day 3 while that of the visibly spoilt white dent maize slurry increased from 0.4 at day $0-2.3$ at day 3 (Fig. 1b).

Behavior of aflatoxin $B$ during fermentation of maize: The concentration of aflatoxin $B$ in the white dent maize slurries of the apparently clean and visibly spoilt maize samples were monitored from day 0 of fermentation through day 3 as shown in Fig. 2. There was a slight increase in the concentration of the toxin in both maize samples from day 0-1 day. For the apparently clean white dent maize slurry, the aflatoxin $\mathrm{B}$ concentration rose from $0.98 \mu \mathrm{g} \mathrm{mL}^{-1}$ at day $0-1.05 \mu \mathrm{g} \mathrm{mL}^{-1}$ at day 1 , while for visibly spoilt white dent maize slurry the concentration rose from $2.2 \mu \mathrm{g} \mathrm{mL}^{-1}$ at day $0-2.55 \mu \mathrm{g} \mathrm{mL}^{-1}$ at day 1
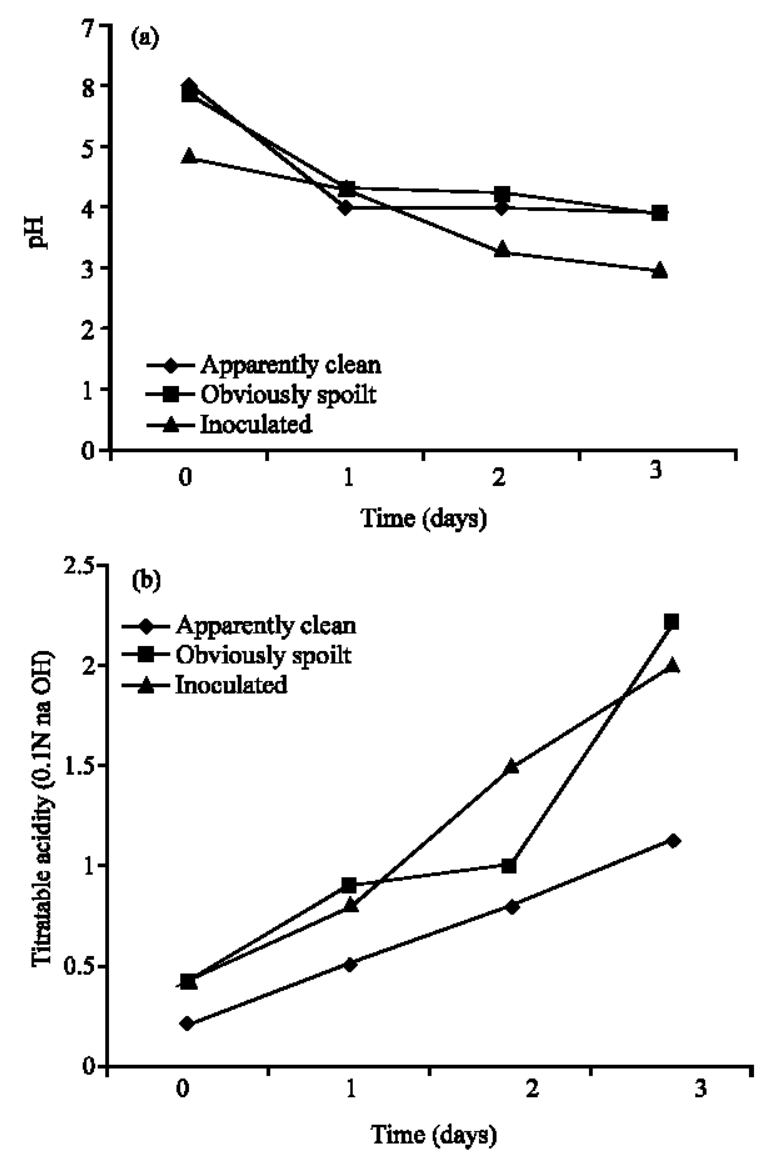

Fig. 1: (a) Changes in $\mathrm{pH}$ of white dent maize slurry during fermentation (b) Changes in titratable acidity of white dent maize slurry during fermentation

(Fig. 2). The concentration of the toxin then persisted through to day 3 during the 3 day fermentation. The average moisture level of the apparently clean maize sample $11.8 \%$ was smaller than that of the visibly spoilt maize sample $18.6 \%$.

This could be as a result of those factors which defined spoilt grains which have exposed the moisture absorbent internal surfaces of the endosperm of the visibly spoilt white dent maize grains (Adegoke and Adeyemi, 2004). The increased physiological activity of the spoilage organisms in the visibly spoilt maize may also be associated with high moisture. Temperature and moisture are the two most important factor governing growth and toxin production in agricultural commodity.

The minimum moisture level for aflatoxin production depends on the nature of substrate and duration of storage (Janardhana et al., 1992). The sharp drop in the $\mathrm{pH}$ as the fermentation progressed from day 0-3 (Fig. la) and a corresponding increase in the titratable acidity (Fig. 1b) was consistent with the result in the fermentation 


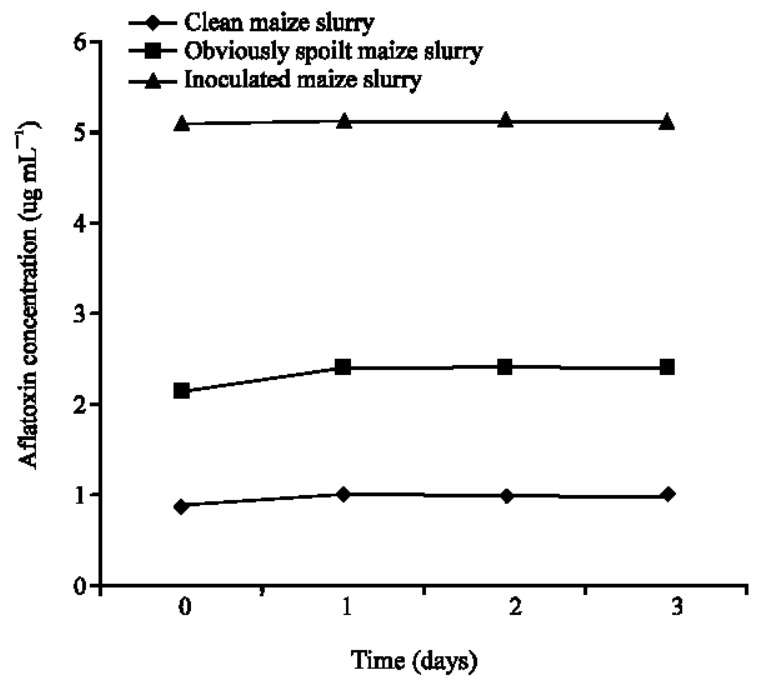

Fig. 2: Changes in concentration of aflatoxin in white dent maize slurry during fermentation

of the traditional Ghanaian corn dough (Mensah et al., 1991) and the Nigeria Ogi (Adegoke and Adeyemi, 2004). However, these changes do not have any effect on the stability of the aflatoxin B present in the fermenting maize as the concentration of the toxin persisted throughout the fermentation period (Fig. 2).

The pertinent need that led to this study was the fact that it has been established that method of preparation and processing of food may account for detoxification (Sall et al., 1988) and destruction of aflatoxin (Mishra and Daradhinger, 1991).

Hence, the study was fashioned to monitor the effect of fermentation, on aflatoxin of maize. Diet is the major way through which humans as well as animals are exposed to aflatoxins. However, occupational exposures in agricultural workers, people working in oil milks and graneries have been reported (Sorenson et al., 1984).

Considering Fig. 2, aflatoxin B was relatively stable to maize fermentation. The concentration rose in the maize samples from day 0-1 probably due to increased libration of the pre-formed aflatoxin in to the medium. However, further increment stopped after day 1 and the already produced aflatoxin remained in the fermentation medium for both maize samples. Studies on the stability of aflatoxin during brewing indicated that it is fairly stable to heat although, some are lost during wort boiling and mashing (Chu et al., 1975). This has a serious health implication since the already formed aflatoxin remained in the medium, being stable to maize fermentation. This implies that if aflatoxin contaminated maize is used in Ogi production, it is not destroyed by the fermentation process. Aflatoxin being relatively stable to heat
(Rehana and Bassapa, 1990) means that the hot water used to gelatinize Ogi may not inactivate or destroy the aflatoxin, substantially as cooking which entails boiling over prolonged period, caused only $41 \%$ maximum inactivation of cooked port (Furtado et al., 1981).

\section{CONCLUSION}

Consequently, fermented maize foods prepared from aflatoxin contaminated maize are left at the mercy of method of preparation and processing to determine the salability, wholesomeness and safety. The United Nation Protein Advisory Group accept a maximum level of $30 \mu \mathrm{g} \mathrm{kg}^{-1}$ of aflatoxin in food supplements for undernourished children in developing countries (Uraih and Ugbadu, 1980) while the German Government permitted levels of aflatoxin in milk for infant is $50 \mathrm{ng} \mathrm{kg}^{-1}$ and for dietetic it is $10 \mathrm{ng} \mathrm{kg}{ }^{-1}, 1991$ ). The concentration of aflatoxin present in these maize slurry samples are high and this study shows that there is an elevated risk of aflatoxicoses in the current and potential use of aflatoxin contaminated maize at village level in Nigeria and suggests the need for control of overall mould contamination of maize grains.

\section{REFERENCES}

AOAC, 1984. Official Methods of Analysis of the Assocition of Official Analytical Chemists. 14th Edn., Association of Official Analytical Chemists, Washington, DC., pp: 1018.

Adegoke, S.A. and S. Adeyemi, 2004. Mycoflora and biochemical changes during fermentation of maize (Zea mays). Savannah. J. Sci. Agric., 3: 75-82.

Alozie, T.C., C.N. Rotimi and B.B. Oyinbo, 1980. Production of aflatoxin by Aspergillus flavus (UBMI) in some Nigerian indigenous beverages and foodstuffs. Mycopathologia, 70: 125-128.

Alpert, M.E., M.S.R. Hutt, G.A. Wogan and G.S. Davidson, 1971. Aflatoxin and hepatoma. Gastroenterology, 62: 171-172.

Anon, A., 1975. Mycotoxins. In: Benjamin Franklin Station, Hobwitz, W. (Ed.). 12th Edn., Associat Official Analysis Chemical, Washington DC, USA.

Bababunmi, E.A., A.O. Uwaifo and O. Bassisr, 1977. Carcinogens contamination of Nigerian foods. Proceedings of the International Congress on Toxicology, Toronto.

Chauvan, J.K. and S.S. Kadan, 1989. Nutritional Improvement of cereals by fermentation. Crit. Rev. Food Sci. Nutr., 28: 349-400. 
Chu, F.S., C.C. Change, S.H. Ashour and N. Prentice, 1975. Stability of aflatoxin B1 and ochratoxin in brewing. Applied Microbiol., 29: 313-316.

Eaton, D.L. and E.P. Gallagher, 1994. Mechanism of aflatoxin carcinogenesis. Ann. Rev. Pharmacol. Toxicol., 34: 135-172.

Furtado, R.M., A.M. Pearson, J.I. Gray, M.G. Hogberg and E.R. Miller, 1981. Effects of cooking on processing upon levels of aflatoxin in meat from pigs fed on contaminated diet. J. Food Sci., 46: 1306-1308.

Groopman, J.D. and C.P. Wild, 2001. Molecular epidemiology: Aflatoxin p53 mutations and liver cancer as a paradigm. http:/www.aspencancercon ference.amc.org/3m2001 groopman.htm.

Howard, S.R. and L.E. David, 1990. Species susceptibility to Aflatoxin $B_{1}$ carcinogenesis. Cancer Res., 50: 615-620.

IARC, 1993. Some Naturally Occurring Substances: Food Items and Constituents, Heterocyclic Aromatic Amines and Mycotoxins. Vol. 56, International Agency for Research on Cancer, Geneva, Switzerland, ISBN-10: 9283212568, pp: 489-521.

Janardhana, R.M., H. Shekara, C. Fandli and J. Lacey, 1992. Role of seed lipids in Aspergillus parasiticus growth and aflatoxin production. J. Sci. Food Agric., 59: 177-181.

Keen, P. and P. Martin, 1971. The toxicity and fungal infestation of foodstuffs in Swaziland in relation to harvesting and storage. Trop. Geo. Med., 23: 44-45.

Kirk, R.S. and R. Sawyer, 1991. Pearson's Composition and Analysis of Food. 9th Edn., Longman Scientific and Technical, Harlow, UK.

Kordylas, J.M., 1990. Processing and Preservation of Tropical and Subtropical Foods. Macmillan, London, UK., pp: 414.

Mensah, P.P.A., A.M. Tomkins, B.S. Draser and T.J. Harrison, 1991. Antimicrobial effect of fermented Ghanain maize-dough. J. Applied Bacteriol., 70: 203-210.

Mishra, N.K. and S. Daradhinger, 1991. Mold flora and aflatoxin contamination of stored and cooked samples of pearly millet in the Raharia Tribal belt of Senthal Pargana, Bihar, India. Applied Environ. Microbiol., 57: $1223-1226$.
Neto, V.R., 1981. Aflatoxin and hepatic cancer: Aflatoxin cancer hepatico. Ciene Cult., 33: 1051-1053.

Nout, M.J.R. and F.M. Rombouts, 1992. Fermentative preservation of plant foods. J. Applied Bacteriol. Symp. Suppl., 73: 1365-1475.

Peers, F.G. and C.A. Linsell, 1973. Dietary aflatoxin and liver cancer: Population based study in Kenya. Br. J. Cancer, 27: 473-484.

Polster, M., J. Smunak, V. Ostry and A. Albrechtova, 1990. Cycloiazonic acid and aflatoxin production by $A$. flavus isolated from foods and animal feeds. Cerkoslovenska Hyg., 35: 144-148.

Rehana, F. and S.L. Bassapa, 1990. Detoxification of aflatoxin $\mathrm{B}_{1}$ in maize by different cooking methods. J. Food Sci. Tech. India, 27: 397-399.

Roderick, J.V. and L. Stoloff, 1970. Determination of concentration and purity of aflatoxin standards. J. Assoc. Off Anal. Chem., 58: 92-95.

Romer, T.R., 1975. Screening method for the detection of aflatoxins in mixed feeds and other agricultural commodities with subsequent confirmation and quantitative measurement of aflatoxins in positive samples. J. Assoc. Off. Anal. Chem., 58: 500-506.

Sall, M.G., A.T. Guiro, A. Kane, N. Sarr, N. Kuakuvi and M. Fall, 1988. Kwashiorkor and aflatoxin. Afr. Med., 27: $355-357$.

Seenappa, M. and I. Nyagahungu, 1983. Presentation of aflatoxin in Ugali and bread made from contaminated maize flour. J. Off Food Sci. Technol., 19: 64-65.

Smela, E.M. and S.C. Sophie, 2001. Elisabeth A Bailey and John $\mathrm{M}$ essingmann: The chemistry and biology of aflatoxin $B_{1}$. Carcinogenesis, 22: 535-545.

Sorenson, W.G., W. Jones, J. Simpson and J.I. Davidson, 1984. Aflatoxin in respirable airborne peanut dust. J. Toxicol. Environ. Health, 14: 525-533.

Uraih, N. and G. Ugbadu, 1980. Incidence of aflatoxin in Nigerian sorghum. Microb. Lett., 14: 29-31.

Van Ransburg, S.J., A. Kirsipuu, L.P. Continho and J.J. van der Watt, 1975. Circumstances associated with the contamination of food by aflatoxin in a high primary liver cancer area. S. Afr. Med. J., 49: 877-883.

Van Veen, A.G. and K.H. Steinkraus, 1970. Nutritive value and wholesomeness of fermented foods. J. Agric. Food Chem., 18: 576-578. 